Aim of the study: Irreversible electroporation is a new, non-thermal ablation technique in the treatment of parenchymal organ tumors which uses short high voltage pulses of electricity in order to induce apoptosis of targeted cells. In this paper the application of this method of treatment in locally advanced pancreatic cancer (LAPC) and liver cancer is analyzed.

Material and methods: Between 04.2014 and 09.2014 two patients with LAPC and one with colorectal liver metastasis (CRLM) were qualified for treatment with irreversible electroporation. Both patients remained under constant observation and control. PubMed/Medline, Embase and Google Scholar databases were searched and eight original reports on irreversible electroporation of pancreatic and liver tumors based on the biggest groups of patients were found.

Results: Two patients with LAPC and one with CRLM were qualified for ablation with irreversible electroporation. In all three patients a successful irreversible electroporation (IRE) procedure of the whole tumor was conducted. In the minimum seven-month follow-up $100 \%$ local control was achieved - without progression.

In the literature review the local response to treatment ranged from $41 \%$ to $100 \%$. The event-free survival rate in six-month observation was $94 \%$.

Conclusions: Ablation with irreversible electroporation is a new non-thermal ablation technique which has been demonstrated, both in the previously published studies and in the cases described in this paper, as a safe and efficient therapeutic method for patients with LAPC and CRLM.

Key words: irreversible electroporation, NanoKnife, ablation, pancreatic cancer, liver metastases.

Contemp Oncol (Pozn) 2016; 20 (1): 39-44 DOI: $10.5114 /$ wo. 2016.57815

\section{Irreversible electroporation in the treatment of locally advanced pancreas and liver metastases of colorectal carcinoma}

\author{
Mateusz Wichtowski ${ }^{1}$, Piotr Nowaczyk ${ }^{1}$, Jacek Kocur ${ }^{2}$, Dawid Murawa ${ }^{1,3}$
}

${ }^{1}$ Oncological and General Surgery Ward I, Greater Poland Cancer Centre, Poznan, Poland ${ }^{2}$ Radiology Department, Greater Poland Cancer Centre, Poznan, Poland

${ }^{3}$ Regional Specialist Hospital in Wroclaw, Research and Development Centre, Wroclaw, Poland

\section{Introduction}

Locally advanced parenchymal organ tumors, described as unresectable, were considered inoperative for many years - hence the search for new methods of treatment, ones without the need to resect. That is why, in the last decade, there has been technological progress in ablation techniques [1].

Ablation is commonly used as a method of treatment of primary and secondary tumors of some parenchymal organs, mostly of the liver and kidneys. In this paper the focus is placed on the treatment of locally advanced pancreatic cancer (LAPC) and colorectal liver metastasis (CRLM) using non-thermal ablation - electroporation.

The most popular techniques of ablation are based on thermal destruction of the source of pathology, and these are radiofrequency ablation (RFA) and microwave ablation (MWA) [1]. Both methods use high temperature to thermally destroy the target area. Cryoablation, which is also listed among the thermal ablation methods, uses the opposite phenomenon - freezing the target area. This method, however, is currently used less frequently.

Thermal ablation techniques (RFA, MWA) are widely used in patients with tumors located in the liver, kidneys and lungs. However, because of the fact that they are thermal methods, they may cause damage of the structures adjacent to the tumor, such as blood vessels, bile ducts, nerves or pancreatic ducts.

Moreover, the flow of blood in the neighboring vessels may cause cooling of the ablation area adjacent to those vessels, and therefore induce the risk of the "heat sink effect" [2, 3]. An additional limitation of the thermal ablation techniques is the size of the tumor - the optimal size of the planned area of ablation should not exceed $3 \mathrm{~cm}$, because the full response to RFA ablation in the case of tumors bigger than $3 \mathrm{~cm}$ is 10-25\% [4-6].

New ablation techniques use the phenomenon of cell electroporation caused by high-voltage electricity. Two types of electroporation can be distinguished - reversible electroporation, which is used in electrochemotherapy (treatment of metastases to the skin of various tumors) and constitutes an important element in the development of transfer of medicine and modified genes into cells, and irreversible electroporation (IRE) [7].

Irreversible electroporation is based on delivering high-voltage electricity through electrodes directly to the tumor, under radiological control [8]. During this procedure a great number of nanopores in the cell membrane are produced. The changes in the membrane are irreversible and the damage to homeostasis caused by them induces apoptosis [9].

In a preclinical study it was evidenced that IRE influences only the cells inside the ablation area, sparing large anatomical structures in the vicinity of 
the tumor, such as vessels, bile ducts, and pancreatic ducts $[10,11]$. Moreover, the "heat sink effect" does not apply to IRE as a non-thermal ablation technique [12].

Colorectal liver metastases are the most common recommendation for surgical treatment of the liver $[13,14]$. Only $10-20 \%$ of the diagnosed cases are qualified for resection [13]. The previous studies on thermal methods of ablation of changes in the liver based on RFA showed an improvement in survivability and quality of life in patients with CRLM who underwent this therapy, as compared with patients treated with chemotherapy [15]. Five-year survival rates with the use of RFA and MWA in colorectal liver metastases are close to the survival rates after radical surgical resection [16].

Changes located in the vicinity of large vessels, such as the portal vein, liver vessels and close to the main bile ducts, are often disqualified from treatment with thermo-

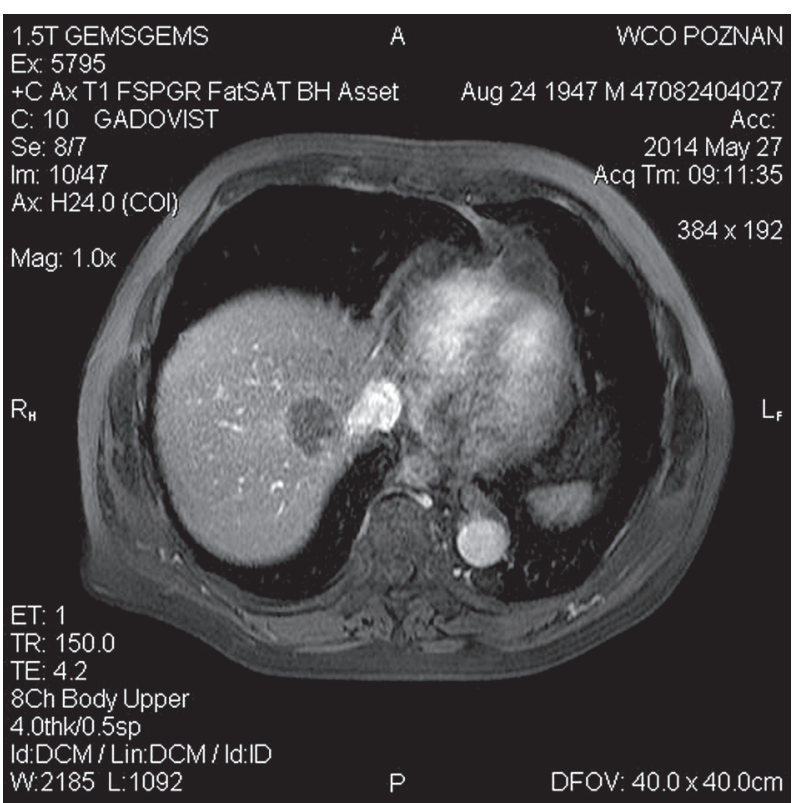

Fig. 1. CRLM 8 segment, before procedure

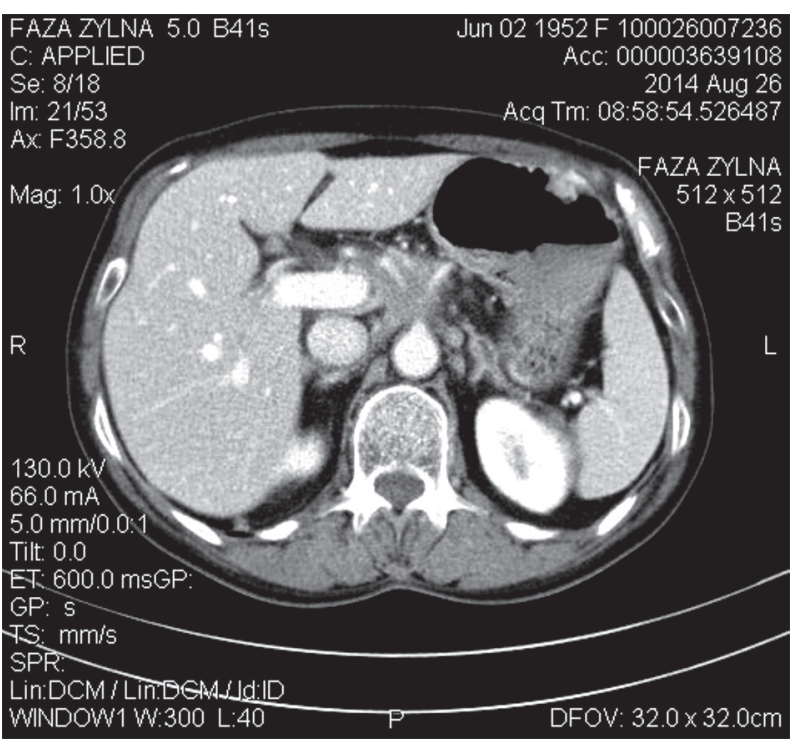

Fig. 2. LAPC, before operation ablation (RFA, MWA) because of the limitations of this method.

Treatment of pancreatic cancer is one of the greatest challenges in contemporary oncology because of its late diagnosis, aggressive course and resistance to most available therapeutic methods [8]. Five-year survival in pancreatic cancer is 3.5\% and one-year survival is 18\% [17]. The location of the pancreas causes patients to be asymptomatic until the process is advanced and the tumor spreads to local large blood vessels, such as the portal vein, celiac artery or superior mesenteric vessels [18]. Only $20 \%$ of the cases are qualified for surgical treatment [19]. In the case of unresectable pancreatic cancer (LAPC) the current standard and practically the only treatment method remains chemotherapy [20].

Even in radical surgical treatment combined with adjuvant chemotherapy in combined modality therapy the achieved five-year survivability is at the level of 10-20\% [21]. Neoadjuvant chemotherapy in borderline resectable LAPC is beneficial as it induces the possibility of resection in $30-40 \%$ of cases [20]. Thermal ablation of the pancreas is used in the case of tumors in a very limited scope. Because of high vascularity of the pancreas a common complication is heavy bleeding. Damaging the pancreatic duct or bile ducts is also possible and creates the risk of further complications in the form of fistulas [8].

\section{Material and methods}

Between 04.2014 and 09.2014 two patients with LAPC and one with CRLM were qualified for treatment with the irreversible electroporation technique. The patients remained under constant observation and control. Each of the patients underwent a detailed preoperative diagnosis and none of the patients were qualified for standard surgical treatment methods. The only alternative for them was palliative chemotherapy.

In this paper eight original reports, based on the biggest groups of patients and related to irreversible electroporation of the pancreas and liver, were also analyzed. They were available on PubMed, Medline, Embase, and Google Scholar databases.

\section{Case descriptions}

A 67-year-old patient was admitted to Oncological and General Surgery Ward I in the Greater Poland Cancer Centre in August 2011 with a diagnosis of colorectal cancer. Histopathological result: tubular adenocarcinoma with mucinous component (G2, pT3, pNO). Adjuvant chemotherapy was applied. There were regular medical checkups in the surgical oncology outpatient clinic.

As a result of a control CT scan in April 2013 a metastasis was diagnosed in the third segment of the liver - the patient was qualified for surgical treatment and resection of the third segment was performed. During subsequent check-ups in April 2014 a metastasis source was diagnosed in the eighth segment, in the area of hepatic vein drainage. The tumor was unresectable, and because of the location it was also not qualified for ablation with thermal techniques. Irreversible electroporation ablation was 
proposed to the patient. The procedure was carried out in June 2014.

The remaining patients with LAPC (both 62 years old) registered in the outpatient specialist center because of generalized pain in the epigastrium and body mass loss. An introductory and later more detailed diagnosis were conducted and in both cases they revealed a pancreatic tumor. The sizes of the tumors were respectively $41 \mathrm{~mm}$ by $40 \mathrm{~mm}$ and $35 \mathrm{~mm}$ by $25 \mathrm{~mm}$. In both cases the tumor infiltrated the superior mesenteric vessels, the celiac artery and left gastric vessels.

At baseline the level of CA199 was respectively $386 \mathrm{U} / \mathrm{ml}$ and $82.83 \mathrm{U} / \mathrm{ml}$ (reference range $0-37 \mathrm{U} / \mathrm{ml}$ ). In one of the patients, unrecognized earlier diabetes was diagnosed. One of the main problems of the patients in the preoperative stage was difficult pain management. Their assessment of it on the VAS (Visual Analogue Scale) scale was $7 / 8$ and they used opioid painkillers several times a day. Ablation with the irreversible electroporation technique was proposed to them (NanoKnife, AngioDynamics, Latham, NY). The procedures were conducted respectively in July and September 2014.

\section{Surgical procedure}

The procedure was performed under general anesthesia with standard hemodynamic monitoring. To prevent arrhythmia induced by IRE the patients were secured with a synchronizer (Accusync, AngioDynamics, Latham, NY) connected to a 5-lead ECG whose purpose was to synchronize the delivered electrical pulses with the diastole phase.

The laparotomies were conducted with Kocher incision and in the case of one patient extended with an upper midline incision. After the preparation of the target area in each case intraoperative ultrasound was performed by a radiologist (BK Medical System Pro Focus device). In the case of pancreatic tumors a core needle biopsy was performed after the localization of the tumor and next, in all cases, the target area was mapped according to the NanoKnife (AngioDynamics, Latham, NY) device protocol. Four needles placed in the tumor were used for the IRE, placed $20 \mathrm{~mm}$ apart, thus creating the planned ablation area. All the needles were placed in parallel with each other to sustain an equal electrical field. A total of four sessions, 90 IRE pulses each, were conducted. According to the indications of the steering system of Nanoknife (AngioDynamics, Latham, NY) successful electroporation of the whole tumor was achieved. The effectiveness of the ablation was assessed in IOUS (intra-operative ultrasound), revealing a hypoechogenic area surrounding the planned ablation area.

\section{Postoperative course}

Postoperative complications, in accordance with CTCAE scale version 3.0 (Common Terminology Criteria for Adverse Events v3.0), were divided into direct, indirect connected with the ablation procedure, and not connected with the procedure.

No case of direct complication connected with the procedure was noted. In the patient with CRLM two compli-

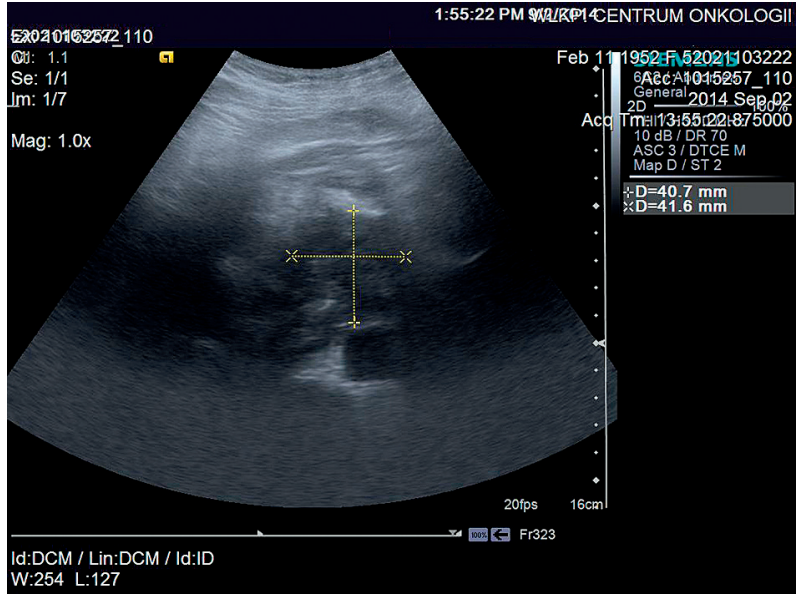

Fig. 3. Intraoperative USG, before IRE

cations indirectly connected with the procedure appeared - jaundice with total bilirubin not higher than 21.55 umol// and an increase of liver aminotransferase (ALAT maximum of $247 \mathrm{U} / \mathrm{l}$, ASPAT $75 \mathrm{U} / \mathrm{l}$ ) and one complication not connected with the procedure - lower respiratory tract inflammation. In patients with pancreatic cancer three indirect complications connected with the ablation were noted pancreatitis, endocrine hypofunction of the pancreas in the form of fluctuation of blood glucose level, and acute kidney failure (maximum creatinine 198.2 umol/l) - and one complication not connected with the procedure: leukocytosis.

After the surgery the average hospitalization period was 8.6 days.

\section{Ambulatory control}

All patients are undergoing regular check-ups of their biochemical and radiology parameters. The first check-up took place a month after the surgery, the subsequent ones every two months. In the CRLM patient the change which

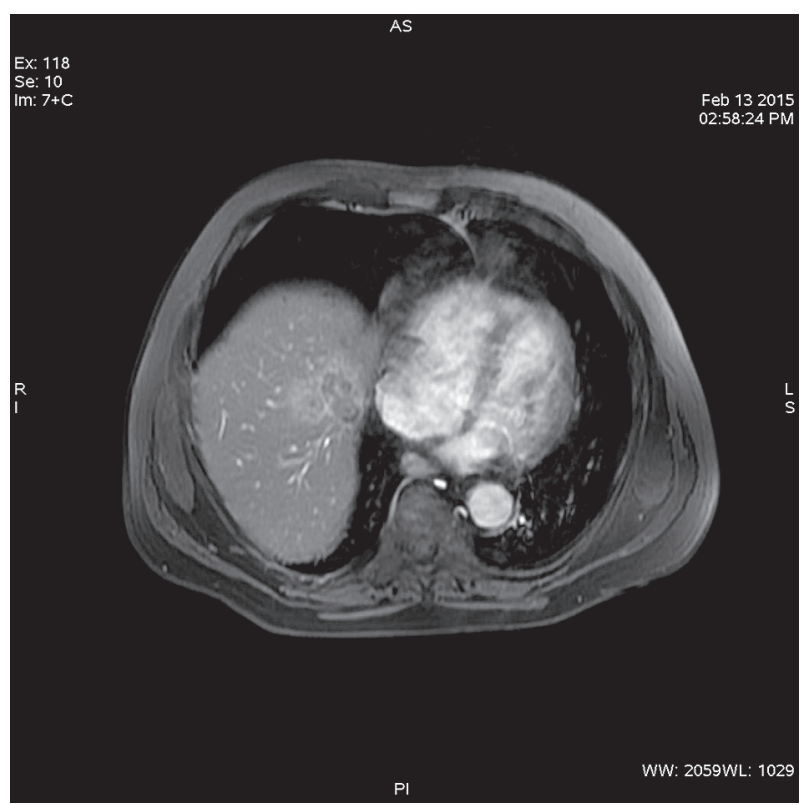

Fig. 4. CRLM, 8 months after IRE 


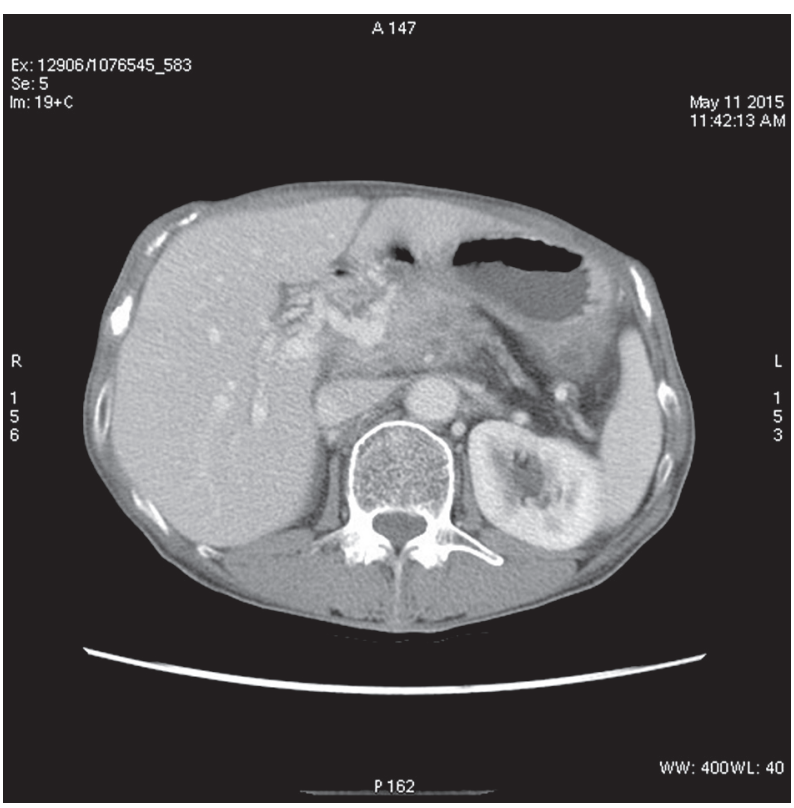

Fig. 5. Tumor of the pancreas, 8 months after IRE

had undergone ablation was monitored radiologically using MRI with the DWI function. The patient did not present a higher level of the marker CEA after the beginning of cancer treatment. The pancreatic cancer patients were monitored biochemically by marking the CA199 parameter and radiologically with a CT scan.

In the CRLM patient from the third month after the procedure until the check up in May 2015 a stable image of the post-ablative scar was observed. The scar was $40 \mathrm{~mm}$ by $20 \mathrm{~mm}$ without signs of limited diffusion, with post-inflammatory fibrosis. No new sources of metastases were observed. In December 2014 the patient was qualified for adjuvant chemotherapy (capecitabine).

In the pancreatic cancer patients, also from the third month after the procedure, a stable image of the post- ablative scar was observed. Their sizes were respectively $35 \mathrm{~mm}$ by $25 \mathrm{~mm}$ and $45 \mathrm{~mm}$ by $35 \mathrm{~mm}$, and they were described as a mass of lower density - necrosis-like. The CA199 level in both patients in the first month after the procedure exceeded the norm at least three-fold (respectively $124.9 \mathrm{U} / \mathrm{ml}$ and $131.30 \mathrm{U} / \mathrm{ml}$ ). After three months the level decreased to less than $80 \mathrm{U} / \mathrm{ml}$ and remained at a similar level in subsequent analyses.

In both patients a significant reduction of experienced pain stemming from the disease was also noted. A month after the procedure it was assessed on the VAS scale at 3-4/10, which allowed for discontinuation of opioid painkillers and introduction of non-opioid ones. In the patient with diabetes type three, who had this disease diagnosed during his cancer treatment, a remission took place. It allowed for discontinuation of oral hypoglycemia-inducing medicine and sustainment of the correct level of glycemia at three months after the procedure. At two months after the procedure both patients began adjuvant chemotherapy (gemcitabine).

All the patients are still under medical supervision, and so far, after a minimum of seven months of observation, show no signs of progression.

\section{Literature review}

A review of the biggest databases was conducted, including PubMed, Medline, Embase, and Google Scholar. The following keywords were used in the search: colorectal liver metastasis and irreversible electroporation, pancreatic cancer and irreversible electroporation. Eight papers which were based on the largest numbers of patients were qualified for the review. Overview papers, papers based on animal models and abstracts were excluded from the review.

Three of the qualified studies concerned prospective research of IRE in the case of primary and secondary liver tumors. Four studies described IRE in the case of pancre-

Table 1. Characteristics of the studies of IRE in liver tumors

\begin{tabular}{|c|c|c|c|c|c|c|c|}
\hline Authors & Year & No. of patients & $\begin{array}{l}\text { Tumor size } \\
\text { (mm) }\end{array}$ & $\begin{array}{l}\text { Complete ablation } \\
\text { rate (\%) }\end{array}$ & $\begin{array}{l}\text { Morbidity } \\
\text { rate (\%) }\end{array}$ & $\begin{array}{l}\text { Follow-up } \\
\text { (months) }\end{array}$ & $\begin{array}{l}\text { Recurrence rate } \\
\text { (\%) }\end{array}$ \\
\hline $\begin{array}{l}\text { Cannon } \\
\text { et al. [23] }\end{array}$ & 2013 & $\begin{array}{l}44 \text { (20 CRLM, } 14 \text { HCC, } \\
10 \text { other metastasis) }\end{array}$ & from 21 to 27 & $100 \%$ & $\begin{array}{l}10 \text { (3-month } \\
\text { rate) }\end{array}$ & 12 & $\begin{array}{l}40.5 \text { (after } \\
12 \text { months) }\end{array}$ \\
\hline $\begin{array}{l}\text { Thomson } \\
\text { et al. [22] }\end{array}$ & 2011 & 32 (17 HCC, 15 CRLM) & from 10 to 50 & $\begin{array}{l}83.3 \text { HCC; } \\
50 \text { CRLM }\end{array}$ & 14.5 & BD & $\mathrm{BD}$ \\
\hline $\begin{array}{l}\text { Scheffer } \\
\text { et al. [16] }\end{array}$ & 2014 & 10 CRLM & $\sim 24$ & $100 \%$ & 10 & BD & BD \\
\hline $\begin{array}{l}\text { Philips } \\
\text { et al. [24] }\end{array}$ & 2013 & 23 CRLM & from 17 to 32 & 100 & 8.5 & 18 & BD \\
\hline
\end{tabular}

Table 2. Analysis of the impact of tumor size and type of surgery on the rate of overall local recurrence-free survival for liver tumors. Cannon et al. [23]

\begin{tabular}{|lcccc|}
\hline & Whole study group & Tumors $<3 \mathbf{c m}$ & IRE percutaneously & IRE in open approach \\
\hline 3 months & $97.4 \%$ & $100 \%$ & $96.4 \%$ & $100 \%$ \\
\hline 6 months & $94.6 \%$ & $100 \%$ & $92.7 \%$ & $100 \%$ \\
\hline 12 months & $59.5 \%$ & $98 \%$ & $50.7 \%$ & $80 \%$ \\
\hline
\end{tabular}


Table 3. Study outcomes of irreversible electroporation for the treatment of locally advanced pancreatic cancer

\begin{tabular}{|c|c|c|c|c|c|c|c|c|c|}
\hline Authors & Year & $\begin{array}{l}\text { No. of } \\
\text { patients }\end{array}$ & $\begin{array}{l}\text { Tumor size } \\
(\mathrm{mm})\end{array}$ & Tumor location & Type of operation & $\begin{array}{c}\text { Complete } \\
\text { ablation rate (\%) }\end{array}$ & $\begin{array}{l}\text { Morbidity } \\
\text { rate (\%) }\end{array}$ & Follow-up & $\begin{array}{l}\text { Event-free } \\
\text { survival }\end{array}$ \\
\hline $\begin{array}{l}\text { Narayanan } \\
\text { et al. [25] }\end{array}$ & 2012 & 54 & $\sim 33$ & $\begin{array}{l}\text { Head: } 6 \\
\text { Body/Tail: } 8\end{array}$ & $\begin{array}{l}\text { Open approach: } 0 \\
\text { Percutaneous } \\
\text { approach: } 14\end{array}$ & $100 \%$ & 14 & 6 months & $\begin{array}{c}6.7 \text { months, } \\
6 \text { months overall } \\
\text { survival (OS) - } \\
70 \%\end{array}$ \\
\hline $\begin{array}{l}\text { Martin RC II } \\
\text { et al. [26] }\end{array}$ & 2013 & 54 & $\sim 32$ & $\begin{array}{l}\text { Head: } 35 \\
\text { Body/Tail: } 19\end{array}$ & $\begin{array}{l}\text { Open approach: } 52 \\
\text { Laparoscopy: } 2\end{array}$ & $100 \%$ & 33 & $B D$ & $\begin{array}{l}14 \text { months, } \\
\text { OS }-20 \text { months }\end{array}$ \\
\hline $\begin{array}{l}\text { Martin RC II } \\
\text { et al. [27] }\end{array}$ & 2012 & 27 & $\sim 29$ & $\begin{array}{l}\text { Head: } 15 \\
\text { Body/Tail: } 12\end{array}$ & $\begin{array}{c}\text { Open approach: } 26 \\
\text { Percutaneous } \\
\text { approach: } 1\end{array}$ & $96 \%$ & 33 & 3 months & Not reported \\
\hline $\begin{array}{l}\text { Philips } \\
\text { et al. [24] }\end{array}$ & 2013 & 59 & $\sim 33$ & $\begin{array}{l}\text { Head: } 34 \\
\text { Body/Tail: } 25\end{array}$ & Not reported & $97 \%$ & 46 & 18 months & 6.7 months \\
\hline
\end{tabular}

atic cancer (two pieces of prospective research and two of retrospective research). One paper presented a multicenter controlled study on the IRE learning curve in the case of parenchymal organ tumors.

Table 1 presents the results of the published studies on IRE in the case of liver tumors. The percentage of successful ablations ranged from $50 \%$ to $100 \%$. The lowest effectiveness was noted by Thomson et al. and it was related to CRLM. It may have been caused by including in the study changes with a diameter larger than $50 \mathrm{~mm}$ and a high percentage of procedures being performed percutaneously [22]. In the study by Thomson et al. high recurrence was also reported for changes of a diameter larger than $40 \mathrm{~mm}$ [22]. In the study by Cannon et al. the percentage of successful ablations was $100 \%$, as high as for HCC (hepatocellular carcinoma) and CRLM [23]. The longest observation period was noted by Philips et al. and it lasted 18 months [24].

Only Cannon et al. established a recurrence rate of liver tumors (HCC and liver metastases); after 6 months it was $6 \%$ and after 12 months 40.5\% [23]. In Table 2 the influence of tumor size and the type of ablation performed on overall local recurrence-free survival indicated in the study by Cannon et al. is presented [23].

They determined that the recurrence rate at the level of $40.5 \%$ in a 12 -month observation period requires significant reduction and thus pointed out the need for more careful selection of patients qualified for IRE, recommended qualifying changes up to $4 \mathrm{~cm}$ in diameter and improving the IRE performance technique.

Table 3 presents reports related to IRE in pancreatic cancer [24-27]. The presented results are very consistent. The average diameter of the tumor was around $32 \mathrm{~mm}$, and the effectiveness of ablation in the planned ablation area was a minimum of $97 \%$. It is worth noting that in the study by Martin et al. in which most of the procedures were performed during laparotomy, the average time free of recurrence was the longest (14 months) as compared with studies in which IRE was performed percutaneously [26]. In another study by Martin et al. attention was brought to pain reduction in patients after the IRE procedure [27]. Pain evaluated on the VAS scale was reduced from 5 to 3 on average.

\section{Discussion}

The irreversible electroporation ablation technique is a new, non-thermal method of irreversible electroporation of parenchymal organ tumors. The first preclinical studies were published in 2007. Rubinsky et al. in their experimental study from 2007, which included 35 pig livers, distinguished three main features which give IRE an advantage over other ablative techniques: the remarkable effectiveness of ablation; the area of IRE ablation close to blood vessels does not suffer from the heat sink effect and thus the cells in the vicinity of the vessels undergo ablation equally with the rest of the ablated part of the tissue; and IRE ablation retains functionality of the blood vessels, bile ducts, urinary tract and nerves which are located in the ablation area [28].

These conclusions were also confirmed by Charpentier et al. in their preclinical study in 2011 [11]. Maour et al. (also in 2007) did a study on rats where they performed IRE on carotid arteries [29]. All animals survived without side effects. Carotid arteries did not show symptoms of aneurysm, thrombus or necrosis after 28 days. Bower et al. in their study on pig pancreas in 2011 placed ablative electrodes $1 \mathrm{~mm}$ from the portal vein and from the superior mesenteric artery [2]. All animals survived postoperatively, without symptoms of necrosis in the pancreas and without embolism in blood vessels.

Since these studies many papers have been published which analyzed the application of IRE in cancer treatment in the liver, pancreas, kidneys, prostate, colon and lungs and achieved promising results as well as showing a short learning curve of the method [24].

Our study demonstrates that IRE could be successfully performed in the treatment of locally advanced pancreas and liver metastases of colorectal carcinoma. We are aware of the imperfections of our study, which is based on a small number of patients and has a relatively short follow-up. Nevertheless, all our patients have achieved a great benefit from treatment: a seven-month follow-up without progression with a good quality of life.

The conclusions from preclinical, clinical and our studies presented above allow us to conclude that the irre- 
versible ablation technique is an interesting therapeutic method for tumors of the liver, pancreas and other organs which have been referred to as unresectable or not fit for ablation. However, 8 years after the first pre-clinical studies, the IRE method leaves many questions unanswered and, what follows, a need for many studies to be conducted. Among these questions are qualification for the procedure, and the use of IRE as a treatment inducing potential resectability. There is a lack of studies directly comparing IRE with thermal ablation techniques. What also needs to be mentioned is that the vast majority of previous studies have been single center studies on low numbers of patients, with a short observation period - there are not enough multicenter, randomized studies on large numbers of patients, whose results could be the basis for formulating recommendations for therapy using irreversible electroporation.

The authors declare no conflict of interest.

\section{References}

1. Ahmed M, Brace CL, Lee FT Jr, Goldberg SN. Principles of and advances in percutaneus ablation. Radiology 2011; 258: 351-69.

2. Bower M, Sherwood L, Li Y, Martin R. Irreversible electroporation of the pancreas: definitive local therapy without systemic effect. J Surg Oncol 2011; 104: 22-8.

3. Patterson EJ, Scudamore CH, Owen DA, Nagy AG, Buczkowski AK Radiofrequency ablation of porcine liver in vivo: Effects of blood flow and treatment time on lesion size. Ann Surg 1998; 227: 559 65.

4. Hur H, Ko YT, Min BS, et al. Comparitive study of resection and radiofrequency ablation in the treatment of solitary colorectal liver metastases. Am J Surg 2009; 197: 728-36.

5. Pompili M, Mirante VG, Rondinara G, et al. Percutaneus ablation procedures in cirrhotic patients with hepatocellular carcinoma submitted to liver transplantation: assessment of efficacy at explant analysis and of safty for tumor recurrence. Liver Transpl 2005; 11: 1117-26.

6. Mazzaferro V, Battiston C, Perrone S, et al. Radiofrequency ablation of small hepatocellular carcinoma in cirrhotic patients awaiting liver transplantation: a prospective study. Ann Surg 2004; 240: 900-9.

7. Charpentier KP. Irreversible electroporatiomn for the ablation of liver tumors. Arch Surg 2012; 147: 1053-61.

8. Moir J, White SA, French JJ, Littler P, Manas DM. Systematic review of irreversible electroporation in the treatment of advanced pancreatic cancer. EJSO 2014; 40: 1598-604.

9. Lee EW, Thai S, Kee ST, et al. Irreversible electroporation: a good novel image-guided cancer therapy. Gut Liver 2010; 4 (Suppl 1): 99-104.

10. Lee EW, Chen C, Prieto VE, Dry SM, Loh CT, Kee ST. Advanced hepatic ablation technique for creating complete cell death: irreversible electroporation. Radiology 2010; 255: 426-33.

11. Charpentier KP, Wolf F, Noble L, Winn B, Resnick M, Dupuy DE. Irreversible electroporation of the liver and liver hilum in swine. HPB (Oxford) 2011; 13: 168-73.

12. Cannon R, Ellis S, Hayes D, Narayanan G, Martin RC 2nd. Safety and early efficacy of irreversible electroporation fo rhepatic tumors in proximity to vital structures. J Surg Oncol 2013; 107: 544-9.

13. Wingo PA, Tong T, Bolden S. Cancer statistics. CA Cancer J Clin 1995; 45: 8-30.

14. Abdalla EK, Adam R, Bilchik AJ, Jaeck D, Vauthey JN, Mahvi D. Improving resectability of hepatic colorectal metastases: expert consensus statement. Ann Surg Oncol 2006; 13: 1271-80.
15. Timmerman RD, Bizekis CS, Pass HI, Fong Y, Dupuy DE, Dawson LA, Lu D. Local surgical, ablative, and radiation treatment of metastases. CA Cancer J Clin 2009; 59: 145-70.

16. Scheffer HJ, Nielsen K, van Tilborg AAJM, et al. Ablation of colorectal liver metastases by irreversible electroporation: result of the COLDFIRE-I ablate-and-resect study. Eur Radiol 2014; 24: 2467-75.

17. Martin RC 2nd, McFarland K, Ellis S, Velanovich V. Irreversible electroporation in locally advanced pancreatic cancer: potential improved overall survival. Ann Surg Oncol 2013; 20: 443-9.

18. Callery MP, Chang KJ, Fishman EK, Talamonti MS, William Traverso $L$, Linehan DC. Pretreatment assessment of resectable and borderline resectable pancreatic cancer: expert consensus statement. Ann Surg Oncol 2009; 16: 1727-33.

19. Warshaw AL, Fernandez-del Castillo C. Pancreatic carcinoma N Engl J Med 1992; 326: 445-65.

20. Von Hoff DD, Ervin T, Arena FP, et al. Increased survival in pancreatic cancer with nab-paclitaxel plus gemcitabine. N Engl J Med 2013; 369: 1691-703.

21. KlinkenbijlJH, Jeekel J, Sahmoud T, et al. Adjuvant radiotherapy and 5-fluorouracil after curative resection of cancer of the pancreas and periampullary region: phase III trial of the EORTC gastrointestinal tract cancer cooperative group. Ann Surg 1999; 230: 776-82.

22. Thomson KR, Cheung W, Ellis SJ, et al. Investigation of the safety of irreversible electroporation in humans. I Vasc Interv Radiol 2011; 22: 611-21.

23. Cannon R, Ellis S, Hayes D, Narayanan G, Martin RC 2nd. Safety and early efficacy of irreversible electroporation for hepatic tumors in proximity to vital structures. J Surg Oncol 2013; 107: 544-9.

24. Philips P, Hays D, Martin RC. Irreversible electroporation ablation (IRE) of unresectable soft tissue tumors: learning curve evaluation in the first 150 patients treated. PLoS One 2013; 8: e76260. doi: 10.1371/journal.pone.0076260

25. Narayanan G, Hosein PJ, Arora G, et al. Percutaneous irreversible electroporation for downstaging and control of unresectable pancreatic adenocarcinoma. J Vasc Interv Radiol 2012; 23: 1613-21.

26. Martin RC 2nd, McFarland K, Ellis S, Velanovich V. Irreversible electroporation in locally advanced pancreatic cancer: potential improved overall survival. Ann Surg Oncol 2013; 20 (Suppl 3): 443-9.

27. Martin RC 2nd, McFarland K, Ellis S, Velanovich V. Irreversible electroporation therapy in the management of locally advanced pancreatic adenocarcinoma. J Am Coll Surg 2012; 215: 361-9.

28. Rubinsky B, Onik G, Mikus P. Irreversible electroporation: a new ablation modality - clinical implications. Technol Cancer Res Treat 2007; 6: 37-48

29. Maor E, Ivorra A, Leor J, Rubinsky B. The effect of irreversible electroporation on blood vessels. Technol Cancer Res Treat 2007; 6: 307-12.

\section{Address for correspondence}

Dawid Murawa, Assoc. Prof.

Oncological and General Surgery Ward I,

Greater Poland Cancer Centre

Garbary 15,

61-866 Poznań, Poland

e-mail: dmurawa@op.pl

Submitted: 3.08.2015

Accepted: 28.12.2015 